\title{
COMPARISON OF DIFFERENT DOSES OF EPIDURAL BUTORPHANOL 2 MG/4 MG AS ADJUVANT TO $0.125 \%$ BUPIVACAINE FOR POSTOPERATIVE ANALGESIA FOR VARIOUS INFRAUMBILICAL SURGERIES
}

\author{
Manisha S. Kapdi ${ }^{1}$, Rupal J. Shah², Dhruvini Patel ${ }^{3}$, Khyati Patel ${ }^{4}$ \\ ${ }^{1}$ Associate Professor, Department of Anaesthesia, NHLM Medical College, Ahmedabad, Gujarat, India. \\ ${ }^{2}$ Associate Professor, Department of Anaesthesia, AMCMET College, Ahmedabad, Gujarat, India. \\ ${ }^{3}$ Resident, Department of Anaesthesia, AMCMET College, Ahmedabad, Gujarat, India. \\ ${ }^{4}$ Resident, Department of Anaesthesia, AMCMET College, Ahmedabad, Gujarat, India.
}

ABSTRACT

\section{BACKGROUND}

Postoperative analgesia is wide spread in this era. There are multimodal techniques available for same. The aim of this study was to compare efficacy, effectiveness, safety, of different doses of butorphanol as adjuvant to Bupivacaine $0.125 \%$ for postoperative analgesia. Study design was randomised double blind comparative study

\section{MATERIALS AND METHODS}

This randomized clinical comparative study was conducted in 50 patients of either sex, aged between 18 - 60 years of ASA grade I and II admitted for elective surgery. Written informed consent was taken and pre-anaesthetic evaluation was done. Epidural catheter was inserted, and all patients were given spinal anaesthesia using $0.5 \%$ hyperbaric bupivacaine (15 mg). In the postoperative period, when patient complained of pain, or VAS score was 3 or more, study drug was given. In group A, epidural bupivacaine (0.125\%) $10 \mathrm{ml}$ and preservative free butorphanol $2 \mathrm{mg}$ diluted to $2 \mathrm{ml}$ with NS, \& in Group B, bupivacaine (0.125\%) $10 \mathrm{ml}$ and preservative free butorphanol $4 \mathrm{mg}$ diluted to $2 \mathrm{ml}$ with NS was given. Parameters observed were; onset of analgesia; duration of analgesia; cardio- respiratory effects and adverse effects. Data was analysed with SPSS Software 16 (IBM, Armonk, NY, USA). Unpaired t test, was used for qualitative data. chi-square test used for categorical data (n, number, \%).

\section{RESULTS}

Age, sex, weight, haemodynamics, and ASA grade were comparable in both groups. Mean onset of analgesia was rapid (4.5+1.06) minutes) in group B when compared to group A $(6.0+1.32$ minutes). This was clinically and statistically significant ( $<<0.001)$. Duration of analgesia was longer in group A which was mean of 410+50.29 minutes compared to group B which was with a mean of 490+39.32 minutes. This was clinically and statistically significant $(p<0.001)$. 24-hour VAS was 3.0+/-1. 2 in Group A, 2. 5+/-1.0 in Group B. Total Analgesic request in 24 hours was $2+/-0.5$ in group A, $1+/-0.2$ in group B. There was no significant difference in heart rate, blood pressure, and respiratory rate, as monitored at regular intervals postoperatively between the two study groups. Regarding adverse reactions, sedation was the main side effect in group B (40\%) patients, in group A it was (36\%). Frequency of pruritis $4 \%$ and nausea-vomiting was more in group B (12\%), in group A it was $0 \%$ \& $8 \%$ respectively. Hypotension and respiratory depression were in $4 \%$ patients in group B which was statistical insignificant. All patients were monitored for 24 hours postoperatively for any untoward effects \& for haemodynamic stability as well as for VAS.

\section{CONCLUSION}

Butorphanol is good adjuvant to $0.125 \%$ bupivacaine in epidural analgesia. $4 \mathrm{mg}$ butorphanol provides prolonged analgesia than 2 mg.

\section{KEY WORDS}

Epidural Butorphanol, Different Doses, Postoperative Analgesia, Infraumbilical Surgeries.

HOW TO CITE THIS ARTICLE: Kapdi MS, Shah RJ, Patel D, et al. Comparison of different doses of epidural butorphanol $2 \mathrm{mg} / 4 \mathrm{mg}$ as adjuvant to $0.125 \%$ bupivacaine for postoperative analgesia for various infraumbilical surgeries. J. Evolution Med. Dent. Sci. 2018;7(53):5618-5623, DOI: $10.14260 /$ jemds/2018/1243

\section{BACKGROUND}

The 'International Association for the Study of Pain' defines pain as "an unpleasant sensory and emotional experience associated with actual or potential tissue damage or described in terms of such damage".

'Financial or Other Competing Interest': None.

Submission 25-11-2018, Peer Review 18-12-2018,

Acceptance 24-12-2018, Published 31-12-2018.

Corresponding Author:

Dr. Manisha S. Kapdi,

Associate Professor

Department of Anaesthesia,

NHLM Medical College \& VS Hospital,

Ahmedabad, Gujarat, India.

E-mail: manisha_kapdi@yahoo.com

DOI: $10.14260 /$ jemds $/ 2018 / 1243$
Postoperative pain causes stress and upsets most of the major organ functions. Hence, relieving pain is one of the fundamental responsibilities of anaesthesiologists.

The epidural route is more popular for postoperative pain management as the technique can be used alone or in combination with general anaesthesia. Epidural technique has been found to provide better pain relief than systemic opioids and also decreased incidence of postoperative complications. ${ }^{(1,2)}$ Epidural administrations of opioids and local anaesthetics have evolved in parallel with intrathecal techniques. $(3,4,5,6,7)$

Among opioids, Morphine, Pethidine, Fentanyl, Sufentanil, Buprenorphine and Butorphanol are most commonly used drugs epidurally.(8,9) In the present study, different doses of 
Butorphanol $2 \mathrm{mg} / 4 \mathrm{mg}$ have been selected as an adjuvant to Bupivacaine $(0.125 \%)$ for postoperative epidural analgesia.

\section{Aims \& Objectives}

A comparison of epidural Bupivacaine and Butorphanol $2 \mathrm{mg}$ versus epidural Bupivacaine and butorphanol $4 \mathrm{mg}$ for post operative analgesia focusing on Onset and duration of analgesia, Cardio respiratory effects, Adverse effects.

\section{MATERIALS AND METHODS}

Fifty adult patients of ASA grade I and II, of either sex, belonging to 18-60 years of age, posted for elective infraumbilical surgeries in general surgery, orthopaedics, gynaecology, urology and plastic surgery were selected for the study.

\section{Group Allocation}

- Randomisation was done by Randomisation table.(10)

- Randomised group Allocation was done by sealed opaque envelope method.

- Execution of sealed envelope was done at time of combined spinal epidural anaesthesia.

\section{Group A}

Bupivacaine (0.125\%) $10 \mathrm{ml}+$ Butorphanol (2 mg) in NS $2 \mathrm{ml}$ of total $12 \mathrm{ml}$ volume.

\section{Group B}

Bupivacaine (0.125\%) $10 \mathrm{ml}+$ Butorphanol (4 mg) in NS $2 \mathrm{ml}$ of total $12 \mathrm{ml}$ volume.

\section{Sample Size}

The sample size for the study was taken for convenience.

\section{Exclusion Criteria}

1. Patients with cardio-respiratory disorders.

2. Patients with renal and/ or hepatic disorders.

3. Contraindications for epidural anaesthesia.

4. Patients physically dependent on narcotics.

5. Patients with history of drug allergy.

6. Head injury cases.

\section{Pre-Anaesthetic Evaluation}

Patients were visited on the previous day of the surgery, a detailed clinical history was taken, and general and systemic examinations were done. Basic laboratory investigations ECG and chest $\mathrm{x}$-ray were carried out routinely on all patients. The patients were explained about the spinal-epidural technique and VAS scale. A written informed consent was taken from each patient.

\section{Premedication}

To allay the anxiety and apprehension all patients were given Tablet Alprazolam $(0.25 \mathrm{mg})$ at $10 \mathrm{pm}$ in the night before the surgery. Patients were kept nil orally for $8 \mathrm{hrs}$ before surgery.

\section{Anaesthesia Technique}

After taking informed consent with all aseptic antiseptic techniques, double spaced combined spinal epidural anaesthesia (CSEA) technique was used.
- Epidural catheter was inserted for postoperative analgesia in L2-3 space with 18-gauge epidural needle by LOR technique (Loss of Resistance) \& epidural catheter of 20 was introduced through it \& advanced 3-4 cm in space. It was fixed and later all patients were operated under spinal anaesthesia given in one space below epidural catheter, using hyperbaric bupivacaine $(0.5 \%) 3$ $\mathrm{ml}(15 \mathrm{mg})$.

- A large bore intravenous line was secured with $18 \mathrm{G}$ cannula and Ringer lactate (R.L.) $10 \mathrm{ml} / \mathrm{kg} / \mathrm{hr}$ infusion was started.

- Routine monitors like ECG, Non-invasive Blood pressure, Pulseoximetry were connected for every case and basal vital signs were recorded before starting the procedure

- Drugs and equipment necessary for resuscitation and general anaesthesia administration were kept ready. An autoclaved spinal-epidural tray was used.

- $\quad$ Sterile disposable epidural set was used and checked for any manufacturing problems.

- Under all aseptic and antiseptic precautions. The epidural space was identified using 18G Tuohy needle with Loss of Resistance (LOR) technique at L2- L3 interspace. Then 20G epidural catheter was passed through the epidural needle in upward direction till about $4 \mathrm{cms}$ of the catheter was in the space. The needle was withdrawn, and the catheter was fixed to the back using adhesive tape. Then spinal anaesthesia was given in the one interspace below the catheter with $23 \mathrm{G}$ Quinke needle using hyperbaric Bupivacaine (0.5\%) 3 ml. (15 mg)

- Level of sensory blockade was accessed by pinprick method, motor block was accessed by modified Bromage score. After achieving sensory level of T6 \& motor block of grade 3 surgery is started. Blood loss, urine output and other routine monitors as described above were observed.

- No narcotics were administered during the intraoperative period.

- $\quad$ Fluid management: To begin with, R.L was infused and maintained with R.L, N.S or D.N.S. Blood was transfused only when indicated.

\section{Post Operative Period}

After completion of the surgery, patient was shifted to recovery room and monitoring was continued. When patient recovered from motor blockade, they were shifted to postoperative ward.

In the postoperative period, when the patient first complained of pain, intensity of pain was assessed using VAS scale. When the VAS score was 4 or more, study drug was given through epidural catheter after confirming its proper position as follows-

\section{Group A}

Received Bupivacaine $(0.125 \%) 10 \mathrm{ml}$ and preservative free Butorphanol $2 \mathrm{mg}$ diluted to $2 \mathrm{ml}$ in NS.

\section{Group B}

Received Bupivacaine (0.125\%) $10 \mathrm{ml}$ and preservative free butorphanol $4 \mathrm{mg}$ diluted to $2 \mathrm{ml}$ in NS. The intensity of pain and pain relief was assessed using VAS 
at $5,10,15,30,60$ minutes 2 hours, and thereafter 2-hourly for 24 hours postoperatively. As and when the patient complains of further pain during the period of observation, intensity of pain was assessed again using VAS to know the effect of the study drug given earlier. If it was 4 or more, rescue analgesia was given in form of Injection Tramadol 50 mg preservative free through epidural catheter slowly as per the institute protocol and the requirements of Epidural Tramadol (Rescue analgesic requests) in 24 hours noted.

\section{Visual Analogue Scale}

Visual analogue scale (VAS) consisted of a $10 \mathrm{~cm}$ line, marked at $1 \mathrm{~cm}$ each on which the patient makes a mark on the line that represents the intensity of pain he/she was experiencing. Mark ' 0 ' represents no pain and mark '10' represents worst possible pain. The numbers marked by the patient was taken as units of pain intensity. VAS was explained to each patient in Preoperative period.

\section{Observations}

1. Onset of analgesia.

2. Duration of analgesia.

3. Haemodynamic effects: Heart rate, blood pressure and respiratory rate.

4. Adverse effects like sedation, pruritis, nausea, vomiting, respiratory depression and hypotension. Urinary retention could not be studied, as patients in the study had indwelling urinary catheter inserted as part of the surgical management.

5. VAS was monitored for 24 hours.

6. Total Analgesic requests in 24 hours were noted.

\section{Onset of Analgesia}

Is the time interval from administration of the study drug (VAS score of 4 or more) to first reduction in pain intensity by at least $10 \mathrm{~mm}$ in VAS.

\section{Duration of Analgesia}

- Is the time interval between onset of analgesia, till patient complaints of pain (VAS score 3 or more) when rescue medication was given.

- Total analgesic requests in $24 \mathrm{hrs}$. were noted.

\section{Sedation}

Quality of sedation after giving the study drug was based on Ramsay sedation assessment scale.

\section{Hypotension}

A fall of $30 \%$ in BP from baseline value.

\section{Respiratory Depression}

A respiratory rate of less than 10 breaths/ min.

\section{Bradycardia}

- A fall of $20 \%$ in pulse rate from base line value.

- $\quad$ Nausea vomiting- 4-point scale.

\section{Management of Adverse Effects Hypotension}

IV fluids and Injection Ephedrine 6 mg kept ready.

\section{Bradycardia}

- Injection Glycopyrrolate $0.2 \mathrm{mg}$ IV.

- Pruritus Shivering-pruritus was treated with inj. Pheniramine maleate. Shivering with ventimask oxygen \& warm fluids.

\section{Respiratory Depression and Deep Sedation}

Supportive measures like Stimulation, Oxygen with nasal prongs and IV Naloxone 0.4 to $2 \mathrm{mg}$ kept ready.

\section{Nausea-Vomiting}

Grade $1 / 2$ head low position, ventimask oxygen \& Injection Ondansetron $4 \mathrm{mg} I \mathrm{~V}$, if profound Grade 3/4 nausea, vomiting

\section{Statistical Methods 11}

- We have used SPSS Software 16 (IBM, Arnmonk, NY, USA) for Statistical analysis.

- Data expressed in mean, range, standard deviations.

- Qualitative data expressed as their measures (no, N, \%)

Unpaired T test (Two tailed, independent) has been used to find the significance of duration of analgesia, onset of analgesia and VAS scores between two groups. Unpaired $T$ test for Age distribution in demographic data, for SBP, DBP, HR, RR.

Chi-square test has been used to find the significance in categorical data like, sex distribution, ASA grade distribution in demographic data, incidence of side effects between two groups, Total no of Analgesic requests in 24 hours.

$\mathrm{P}>0.05$ is non-significant (NS).

$\mathrm{p}<0.05$ is significant $(\mathrm{S})$,

$\mathrm{p}<0.001$ is highly significant (HS)

\section{RESULTS}

Fifty adult patients belonging to ASA grade I and II, of either sex, in age group between 18- 60 years, posted for elective lower abdominal and lower limb surgeries under spinal anaesthesia were selected for the study. They were randomly allocated to two groups with 25 patients in each group. Randomisation was done by sealed envelope method.

\section{In Group A}

Bupivacaine (0.125\%) $10 \mathrm{ml}+$ Butorphanol (2 mg) were used as the study drug.

\section{In Group B}

Bupivacaine (0.125\%) $10 \mathrm{ml}+$ Butorphanol (4 mg) were used as the study drug for the relief of postoperative pain. This comparative clinical study was undertaken to study the efficacy based on onset of analgesia, duration of analgesia and adverse effects.

\begin{tabular}{|c|c|c|c|}
\hline $\begin{array}{c}\text { Parameters } \\
(\text { Mean +/- SD) }\end{array}$ & $\begin{array}{c}\text { Group A } \\
(n=25)\end{array}$ & $\begin{array}{c}\begin{array}{c}\text { Group B } \\
(n=25)\end{array} \\
\end{array}$ & $\begin{array}{c}\text { Pvalue } \\
\text { (Inference) }\end{array}$ \\
\hline Age (yrs.) & $39 \pm 11.58$ & $40 \pm 11.63$ & $>0.05(\mathrm{NS})$ \\
\hline Sex Ratio (M:F) & $12: 13$ & $12: 13$ & $>0.05$ (NS) \\
\hline Weight (kg) & $67 \pm 6.04$ & $68 \pm 5.58$ & $>0.05$ (NS) \\
\hline Pulse (per minute) & $77 \pm 8.13$ & $77 \pm 8.11$ & $>0.05$ (NS) \\
\hline SBP (mm of $\mathrm{Hg})$ & $123 \pm 9.42$ & $122 \pm 10.01$ & $>0.05(\mathrm{NS})$ \\
\hline DBP (mm of $\mathrm{Hg}$ ) & $75 \pm 7.47$ & $75 \pm 6.48$ & $>0.05$ (NS) \\
\hline RR (per minute) & $14 \pm 1.41$ & $14 \pm 1.45$ & $>0.05(\mathrm{NS})$ \\
\hline ASA (I:II) & $19: 6$ & $19: 6$ & $>0.05$ (NS) \\
\hline
\end{tabular}


Both groups were also comparable with respect of sex distribution, weight, haemodynamics characteristics and ASA Grade ( $p>0.05$ ) of patients before study drug given.

\begin{tabular}{|c|c|c|c|c|}
\hline $\begin{array}{c}\text { Parameters } \\
\text { (Mean+/-SD) }\end{array}$ & $\begin{array}{c}\text { Group A } \\
(\mathbf{n = 2 5 )}\end{array}$ & $\begin{array}{c}\text { Group B } \\
(\mathbf{n = 2 5})\end{array}$ & $\begin{array}{c}\text { P } \\
\text { value }\end{array}$ & Inference \\
\hline $\begin{array}{c}\text { Onset of analgesia } \\
\text { (mins) }\end{array}$ & $\begin{array}{c}6.0+/- \\
1.32\end{array}$ & $4.5+/-1.06$ & $<0.001$ & HS \\
\hline $\begin{array}{c}\text { Duration of analgesia } \\
\text { (mins) }\end{array}$ & $\begin{array}{c}410+/- \\
50.29\end{array}$ & $\begin{array}{c}490+/- \\
39.32\end{array}$ & $<0.001$ & HS \\
\hline $\begin{array}{c}\text { Total analgesic } \\
\text { requests in 24 hrs.(no.) }\end{array}$ & $2+/-0.5$ & $1+/-0.2$ & $<0.001$ & HS \\
\hline $\begin{array}{c}\text { VBP (mm of Hg) in } 24 \\
\text { hrs }\end{array}$ & $3.0+/-1.2$ & $2.5+/-1.0$ & $<0.05$ & S \\
\hline $\begin{array}{c}\text { DBP (mm of Hg) in 24 } \\
\text { hrs }\end{array}$ & $68+/-6$ & $66+/-8$ & $>0.05$ & NS \\
\hline $\begin{array}{c}\text { RR (per minute) in 24 } \\
\text { hrs }\end{array}$ & $14+/-3$ & $12+/-4$ & $>0.05$ & NS \\
\hline $\begin{array}{r}\text { Table 2. Analgesic \& Haemodynamic Characteristics after } \\
\text { Study Drug }\end{array}$ \\
\hline
\end{tabular}

\begin{tabular}{|c|c|c|c|c|}
\hline \multirow{2}{*}{ Adverse Effects } & \multicolumn{2}{|c|}{ Group A } & \multicolumn{2}{c|}{ Group B } \\
\cline { 2 - 5 } & No. & \% & No. & \% \\
\hline Sedation & 9 & 36 & 10 & 40 \\
\hline Pruritis & 0 & 0 & 1 & 4 \\
\hline Nausea-Vomiting & 2 & 8 & 3 & 12 \\
\hline $\begin{array}{c}\text { Respiratory } \\
\text { Depression }\end{array}$ & 0 & 0 & 1 & 4 \\
\hline Hypotension & 0 & 0 & 1 & 4 \\
\hline \multicolumn{4}{|c}{ Table 3. Adverse Effects } \\
\hline
\end{tabular}

\section{Sedation}

Was observed in 9 patients (45\%) of Group A and 3(12\%) patients of Group B. This was statistically significant $(\mathrm{p}<0.05)$.

\section{Pruritis}

Was seen 1 patient (4\%) of group B and in none of the patients of group A which was statistically significant $(p<0.05)$. It was treated with inj. Chlorpheniramine maleate.

\section{Nausea and Vomiting}

Were observed in 2 patients (8\%) in group A and in 3 patients $(12 \%)$ in group B which was statistically significant $(\mathrm{p}<0.05)$.

\section{Respiratory Depression}

Was seen in only 2 patients $(8 \%)$

\section{Hypotension}

In only 1 patient (4\%) of group B and in none of the patients of group A. These were statistically insignificant ( $p>0.05)$.

\section{Sedation Score/Ramsay Sedation Score of 2 or 3 was observed}

In 9 patients (36\%) in group A whereas 10 patients (40\%) in group B had sedation of RSS score $2 / 3$ which was statistically significant $(\mathrm{p}<0.001)$. The quality of sedation was acceptable in the interest of patients' wellbeing. No airway intervention required in any patient.

Total analgesic requests in 24 hours was 2+/-0.5 in group A, \& in it was $1+/-0.2$ in group $B$ which states that butorphanol dose dependently provide analgesia. More analgesia \& less analgesic requests in group B suggest it.

\section{DISCUSSION}

The present comparative study done to assess the efficacy and safety of epidural Bupivacaine and Butorphanol versus epidural Bupivacaine and Fentanyl for the management of postoperative pain in lower abdominal and lower limb surgeries. A total of 50 patients belonging to age groups 1860 years of ASA grade I-II have been taken. Male and female patient ratio was equal Patients undergoing elective lower abdominal and lower limb surgeries in general surgery, orthopaedics, gynaecology, urology and plastic surgery were selected. During the preoperative assessment patients were explained about the epidural procedure and VAS score.

Pre-medication Tablet Alprazolam $0.25 \mathrm{mg}$ orally was given the night before the surgery. Patients were randomly divided into two groups of 25 each, Group A - Bupivacaine and Butorphanol $2 \mathrm{mg}$ and Group B - Bupivacaine and Butorphanol $4 \mathrm{mg}$. Epidural catheter was inserted and all patients were given spinal anaesthesia. In the postoperative period, when patient complained of pain, or when VAS score was 4 or more, patients in group A received epidural Bupivacaine $0.125 \% 10 \mathrm{ml}$ and Butorphanol $2 \mathrm{mg}$ diluted to 2 $\mathrm{ml} \mathrm{NS}$ and patients in group BF received epidural Bupivacaine $0.125 \% 10 \mathrm{ml} \&$ inj. Butorphanol $4 \mathrm{mg}$ diluted to $2 \mathrm{ml}$ in NS. Observations recorded are Onset of analgesia, Duration of postoperative analgesia, Haemodynamic stability and adverse effects.

\section{Onset of Analgesia}

In our study, the mean time for onset of analgesia in group A was $6 \pm 1.32$ minutes and in group $B$ was $4.5 \pm 1.06$ minutes. Majority of patients in group A had onset of analgesia between 4-6 minutes whereas in group B between 2-4 minutes. Statistical analysis showed that onset of analgesia was delayed in group A compared to group B ( $\mathrm{p}<0.001)$.

Mok et al,12 in 1986 did a study to evaluate the analgesic efficacy and safety of epidural Butorphanol $4 \mathrm{mg}$ in comparison to that of epidural morphine $5 \mathrm{mg}$ in patients with postoperative pain. Onset of pain relief with epidural Butorphanol appeared at 15 minutes.

Aswini A. et al,13 in 2009 conducted a comparative study of epidural Butorphanol $4 \mathrm{mg}$ and epidural Fentanyl $100 \mu \mathrm{g}$ for the relief of postoperative pain in lower abdominal and lower limb surgeries. The onset of analgesia was clinically and statistically significantly late (6 minutes) in Butorphanol group when compared to Fentanyl group (3 minutes).

\section{Duration of Analgesia}

In the present study, duration of analgesia in group A was $410 \pm 50.29 \mathrm{~min}$ and in group B was $490 \pm 39.32 \mathrm{~min}$. $(\mathrm{p}<0.001)$.

Less analgesic requests, Less VAS in $24 \mathrm{hrs,} \mathrm{more}$ duration of analgesia in group B suggest dose dependent increased analgesia with $4 \mathrm{mg}$ butorphanol.

Mok et al, in $1986^{12}$ concluded that duration of analgesia with Butorphanol $4 \mathrm{mg}$ averaged $5.4 \mathrm{hrs}$.

Shivakumar T. C. et al ${ }^{14}$, in 2006 evaluated analgesic efficacy and side effects of 2 doses of epidural Butorphanol in lower abdominal surgeries. Patients were randomly assigned to three groups to receive epidural Bupivacaine $0.5 \% 16 \mathrm{ml}$ ( $\mathrm{n}=25$ control group I), Bupivacaine 0.5\% $15 \mathrm{ml}+1 \mathrm{ml} 2 \mathrm{mg}$ 
Butorphanol ( $\mathrm{n}=25$, group II) and Bupivacaine $0.5 \% 14 \mathrm{ml}+2$ $\mathrm{ml}$ of $4 \mathrm{mg}$ Butorphanol ( $\mathrm{n}=25$, group III). Maximum patients demanded rescue analgesics in Group I (36\%) and Group II $(32 \%)$ at $7^{\text {th }}$ hour and in group III ( $\left.40 \%\right)$ at $9^{\text {th }}$ hour.

Neerja Bharti et $\mathrm{al}^{15}$ in 2009. The duration of analgesia was prolonged in patients receiving Butorphanol $(2 \mathrm{mg}, 4$ $\mathrm{mg}$ ) with Bupivacaine $(0.125 \%)$ combination (8.68 $\pm 0.82 \mathrm{hrs}$, $9.82 \pm 0.54 \mathrm{hrs}$ ) as compared with Butorphanol alone (4.35 \pm 0.66 hrs; $\mathrm{P}<0.05$ ).

Aswini A. et $\mathrm{al}^{13}$ in 2009 Duration of analgesia was clinically and statistically longer in Butorphanol group (350 minutes) in comparison to Fentanyl group (230 minutes).

\section{Haemodynamic and Respiratory Effects}

In the present study heart rate, blood pressure and respiratory rate remained stable throughout the observatory period. 1 patient in group B had hypotension (Fall in systolic BP $<20 \%$ of basal reading) and 2 patients in group B had respiratory depression $(\mathrm{RR}<10 / \mathrm{min})$ which was not statistically significant $(\mathrm{p}>0.05)$. Our study can be compared to the following studies- Premila Malik, Chhavi Manchanda, Naveen Malhotra ${ }^{16}$ in their study showed that there were no significant changes in pulse rate, systolic and diastolic BP, RR and $\mathrm{SpO} 2$ in the 2 groups at different time intervals throughout the 24 hours study period ( $p>0.05$ ).

Aswini A. et al ${ }^{13}$ in 2009 opined that there were no significant changes in pulse rate, BP and RR in either group throughout post operative period.

\section{Adverse Effects}

\section{Sedation}

It was the main side effect group A which constituted 45\% compared to B group (12\%). Majority of the patients had mild sedation, patient sedated but arousable. This was statistically significant.

Catherine 0 Hunt ${ }^{17}$ in his study has reported a higher incidence of sedation with epidural Butorphanol and is a dose dependent side effect.

\section{Pruritis}

In our study none of the patients in group A had pruritis and 4 patients (16\%) in group B had pruritis which was statistically significant $(\mathrm{p}<0.05)$.

Premila Malik, Chhavi Manchanda, Naveen Malhotra16 2006 showed that pruritis was higher in epidural fentanyl group than butorphanol group. $(\mathrm{p}<0.05)$.

\section{Nausea and Vomiting}

In our study 2 patient in group A had nausea-vomiting whereas in group B 3 patients had nausea-vomiting which was significant statistically $(\mathrm{p}<0.05)$.

No patients on epidural Butorphanol had nausea or vomiting in study conducted By Catheline 0 Hunt et al. ${ }^{17}$

Premila Malik, Chhavi Manchanda, Naveen Malhotra ${ }^{16}$ in 2006 showed that the incidence of nausea and vomiting was higher in Fentanyl group than butorphanol group.

\section{Respiratory Depression and Hypotension}

In our current study, in group B 2 patients had respiratory depression and 1 patient had hypotension and in none of the patients in group B had hypotension or respiratory depression which were not significant $(\mathrm{p}>0.05)$.

No patients had respiratory depression or hypotension with Butorphanol in studies conducted by Catherine 0 Hunt et al in 1989.17

\section{CONCLUSION}

Epidural butorphanol is safe, effective \& dose dependent in providing good pain relief of moderate duration in the postoperative period and is associated with minimal adverse effects. $4 \mathrm{mg}$ is more efficient than $2 \mathrm{mg}$ for postoperative analgesia.

\section{REFERENCES}

[1] Wyner WE. Four cases of tubercular meningitis in which paracentesis of the theca vertebralis was performed for the relief of fluid pressure. Lancet 1891;137(3531):981-2.

[2] Kar P. A comparative study between epidural butorphanol with bupivacaine and bupivacaine alone for intra-operative and post-operative analgesia in lower limb orthopaedic surgeries. Int J Res Med Sci 2016;4(10):4251-5.

[3] Behar M, Magora F, Olshwang D, et al. Epidural morphine in treatment of pain. Lancet 1979;313(8115):527-9.

[4] Brill S, Gurman GM, Fisher A. A history of neuraxial administration of local analgesics and opioids. Eur J Anaesthesiol 2003;20(9):682-9.

[5] Stoelting RK. Opioid agonists and antagonists. In: Pharmacology and physiology in anaesthetic practice. $3^{\text {rd }}$ edn. Lippincott Raven 1999:103-5.

[6] Stoelting RK. Pharmacology and physiology in anaesthesia practice. $3^{\text {rd }}$ edn. United States of America: Lippincott - Raven publishers 1999:628-33.

[7] Rutter DV, Skewes DG, Morgan M. Extradural opioids for postoperative analgesia. A double-blind comparison of pethidine, fentanyl and morphine. Br J Anaesth 1981;53(9):915-19.

[8] Ameer B, Salter FJ. Drug therapy reviews: evaluation of butorphanol tartrate. Am J Hosp Pharm 1979;36(12):1683-91.

[9] Saxena AK, Arava SK. Current concepts in neuraxial administration of opioids and non-opioids: an overview and future perspectives. Indian J Anaesth 2004;48(1):13-24.

[10] Randomisation. Available from http://www.randomisation.org

[11] Rosnr B. Fundamentals of biostatistics. 5th edn. Duxbury 1999:80-240.

[12] Mok MS, Tsai YJ, Ho WM. Efficacy of epidural butorphanol compare to morphine for the relief of postoperative pain after caesarean section. Anaesthesiology 1986;65:A175.

[13] Ashwini A. A comparative study of epidural butorphanol and epidural fentanyl for the relief of postoperative pain in lower abdominal and lower limb surgeries. Sri Devaraj Urs Medical College Kolar 2009.

[14] Shivakumar TC. Epidural butorphanol - bupivacaine for analgesia during lower abdominal surgeries - a comparison of two doses. Bangalore Medical College Bangalore 2006. 
[15] Bharti N, Chari P. Epidural butorphanol-bupivacaine analgesia for postoperative pain relief after abdominal hysterectomy. J Clin Anesth 2009;21(1):19-22.

[16] Malik P, Manchanda C, Malhotra N. Comparative evaluation of epidural fentanyl and butorphanol for postoperative analgesia. J Anaesth Clin Pharmacol 2006;22(4):377-82.
[17] Hunt CO, Naulty JS, Malinow AM, et al. Epidural butorphanol-bupivacaine for analgesia during labour and delivery. Anesth Analg 1989;68(3):323-7. 